of John Banister of Cobham, Surrey, Baron of the Exchequer. John Banister, the anatomist, saw military service as surgeon to the forces sent to relieve Havre in 1563, under the command of the Earl of Warwick.

We regret that we are unable to give any further facts about Richard Banister's grandfather. We should have surmised that some details ought to have been forthcoming about a man in his position; but Mr. Harvey Bloom was unable to find his will at Somerset House; though he sent us notes of the wills of four Surrey Banisters of the XVIth century; of these that of John Banester, clerk, parson of Schire (Shere) dated 24 February, 1514, may be a reference to a collateral ancestor. He desired to be buried in the church of the Friars Preachers of Guildford. He mentions his nephew, Robert, and his children, Richard, John, Nicholas, William, Thomas, Oliver, Anne and Agnes. He left a silver cup to the Earl of Surrey and another to Sir John Legh of Stokewell, Knt. The will was proved 14 January, 1516-1ז (P.C.C. 19, Holder). It will be noted that the name of his second son was John.

\title{
VOLUMINOUS ORBITO-CRANIAL OSTEOMA. CONSECUTIVE CEREBRAL ABSCESS, OF NASAL ORIGIN
}

\author{
B Y \\ J. N. Roy, M.D., F.A.C.S. \\ PROFESSOR TO THE UNIVERSITY OF MONTREAL
}

IN 1930, I published the case report of a young girl, who had consulted me for a large osteoma of the orbit. This tumour I had removed by a supra-ciliary incision; and the eye conserved its entire physiological function. Besides this tumour, my patient presented, on the corresponding side, a peripheral facial paralysis, and by elimination of the possible causes, I have classified this affection, which has been cured within four months, as being a frigore. The ethmoid bone had been the point of origin of the neoplasm, and in spite of its radical removal, a relapse came on the same place, a few years later. The great interest of the present case report is that this time the osteoma, originating in the ossification of a fibroma, had at first invaded the orbit, afterwards extended to the cranial cavity, and spread infection to the brain. During operation I discovered a vast abscess of the frontal lobe. Considering these facts, and the medical literature perused, I believe I can say that this case report is the first one ever published on such a subject. This is the history of my patient, 
who died of diffuse leptomeningitis twenty-eight hours after operation.

Case report.-Miss C.N., aged 24 years, was admitted to my service at Notre-Dame Hospital, on January 26, 1933, for troubles of the right oculo-frontal region. This patient, from whom I had already removed an osteoma of the orbit weighing twenty-eight grammes, on May 8,1925, related that since the operation she enjoyed an excellent state of health until October, 1931. She noticed from this moment a sensation of fulness in the orbital cavity, without feeling any pain. The eye was projected forward very slowly, but the vision remained good, and she never complained of diplopia. Headaches localized to the right and starting from the frontal region, appeared in about one month.

On examination I observed a slight direct exophthalmos of the right eye, which nevertheless conserved all its mobility. The lids cover exactly the cornea, whose sensibility is perfect. The pupilla reacts well to light. There exists epiphora, but the lacrymal ducts are permeable. The papilla is normal, so are the membranes of the fundus of the eye. With the diploscope of Rémy, I noticed a good fusion of images. Nothing interesting was found in the left eye and vision of both eyes was $1 / 3$. Though, after the correction of a mixed astigmatism it rose to $2 / 3$.

$$
\begin{aligned}
& \text { O.D. } 105^{\circ}+2.25-0.75=2 / 3 . \\
& \text { O.S. } 120^{\circ}+2-0.50=2 / 3 .
\end{aligned}
$$

The right orbital roof is painful on pressure, and with the little finger I felt a neoplasm on luxating the globe slightly downwards. The patient complains of headaches localized in the frontal region of the corresponding side.

On anterior rhinoscopy I found a right nasal fossa without pús, absolutely free, but presenting anosmia. There exists to the left a slight spur of the septum. On this side the sense of smell is normal.

The pharynx and the cavum offer nothing particular.

Diaphanoscopy allows us to see that all sinuses of the face are quite transparent.

In the presence of this exophthalmos in my patient, already operated on for an osteoma, I immediately thought of a relapse, and asked for a Roentgenogram. And this by Dr. Laquerrière gave me the following information.

"On the radiogram of the face: complete opacity of the right orbit ; corresponding frontal sinus normal."

"On the radiogram of profile: nippled bony tumour, more voluminous than a large nut, localized forward in the posterior part of the orbit, and in rear in the cranial cavity." (See Fig. 1.)

The patient having a temperature of $102.4^{\circ} \mathrm{F}$. was immediately ordered to bed, and I told her that before removing the tumour, it would be necessary first to enucleate the eye, and that operative 
intervention might offer serious consequences. Impressed by these explanations, she asked to be allowed to consult her family. During the following days, the symptoms grew considerably worse. Indeed, headaches became more intense, temperature oscillated between $97^{\circ}$ and $100^{\circ} \mathrm{F}$., and she had vomiting. From time to time she suffered

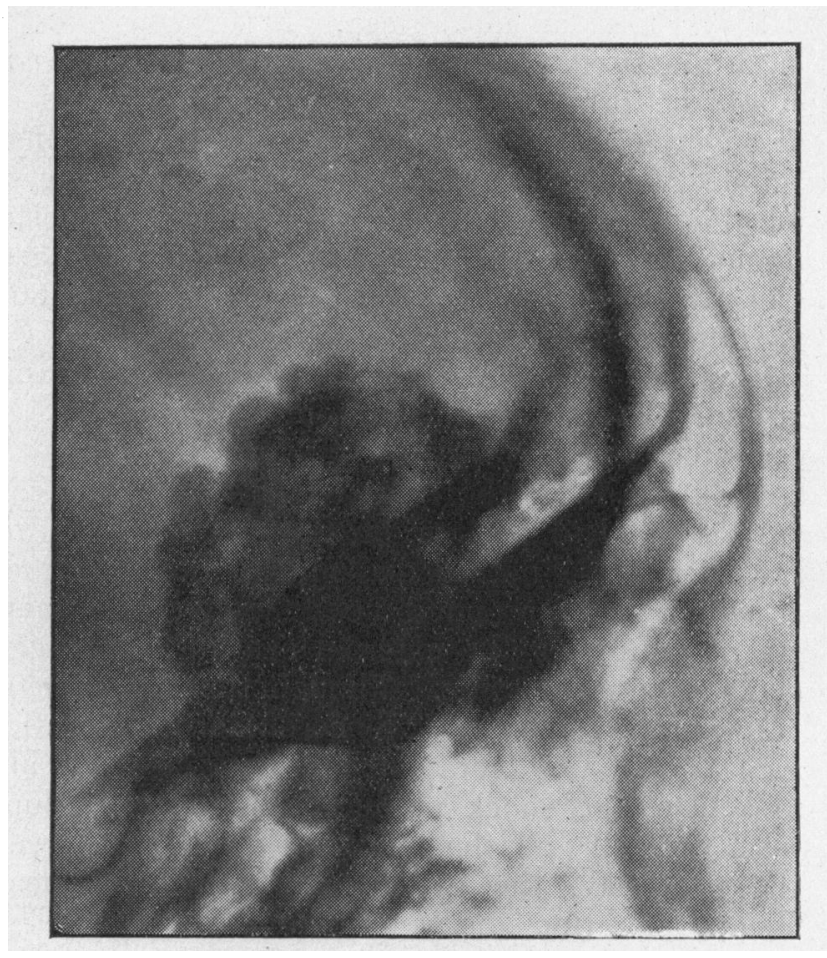

FIG. 1.

Orbito-cranial osteoma.

want of sleep or torpor. By lumbar tapping we obtained a clear liquid which escaped from the canula without pressure. Analysis of this liquid gave the following report:-

Lymphocytosis normal.

Bacteriological examination negative.

Albumen 0 gr. 60.

Blood test gave a negative Wassermann reaction, and a normal quantity of urea.

Traces of albumen in urine, and absence of sugar.

During the second week after the admission of the patient to the hospital, nervous troubles increased, and headaches became more severe and persistent. She presented always a little hyper- or 
hypothermy, accompanied by somnolence or want of sleep. Nevertheless, the discs were not choked, and vision was maintained. On February 9, I reiterated the advice to undertake an intervention which, this time, was accepted to take place on the following day.

Operation.- - In the presence of the condition of apathy manifested by the patient, the anaesthetist administered rectally to her 6 c.c. of avertin, which produced an ideal sleep. After asepsis of the field of operation, I practised an external canthotomy, followed by an exenteration of the orbit. I then discovered a nippled osteoma filling all the superior half of this cavity. By its adhesions, it was easy to conclude that the neoplasm had its origin in the ethmoid bone. Using the gouge and mallet, I freed its nasal implantation. As the tumour was spongy at certain places, and as. I did not wish to fracture the thin walls of the orbital cone, in trying to remove it altogether, I parcelled it with a cutting forceps. I mobilised with an extreme prudence its cranial part with a lever, once I arrived at the bottom of the cavity. During these manoeuvres, my. surprise was great when I saw gradually flowing out from the frontal lobe about 20 c.c. of pus. Needless to say the last portion of the osteoma was removed trying as far as possible not to disseminate the infection. The intervention, which had presented no difficulty, was finished by a few points of suture to the external canthus, drainage of the abscess, and an aseptic dressing. Though the loss of blood was very small, I prescribed 500 c.c. of glucosed serum in intravenous injection and 2 c.c. of coramine intramuscularly, in order to attenuate a little the shock produced by the operation. The awakening was normal, and the following night sleep was calm. However, the next day, the patient complained of headaches, had incontinence of urine and vomiting. Fever reappeared and gradually increased. She became unconscious in spite of all the stimulants administered, and began then to be delirious. The breathing rose to 40 , the pulse to 160 , and she died twenty-eight hours after the operation with a temperature of $103 \cdot 1^{\circ} \mathrm{F}$.

The autopsy, performed by associate Prof. Simard, permitted us to make, among others, some very interesting observations of the orbito-cranial region.

"The cadaver is one of a young woman well constituted but emaciated."

"The right eye is absent as well as the orbital roof. The orbital cavity is filled by a clot of blood which is continuous with another clot adherent to the right frontal lobe of the brain. The right frontal sinus is intact."

"On the inferior side of this lobe, exists a loss of substance in the form of a cupola, of four and one half centimetres in the transverse diameter, of four centimetres in the antero-posterior direction, 
and of a depth of two centimetres. This loss of substance is replaced by a red blackish mass, striated with grey bands, which is continuous with the clot of the orbit."

"The olfactory bulb and nerve of the same side are destroyed."

"The borders of this cupola, seen with the microscope, are constituted by parcelled cerebral tissue, strongly infiltrated with red corpuscles. The bottom is carpeted by a purulent layer."

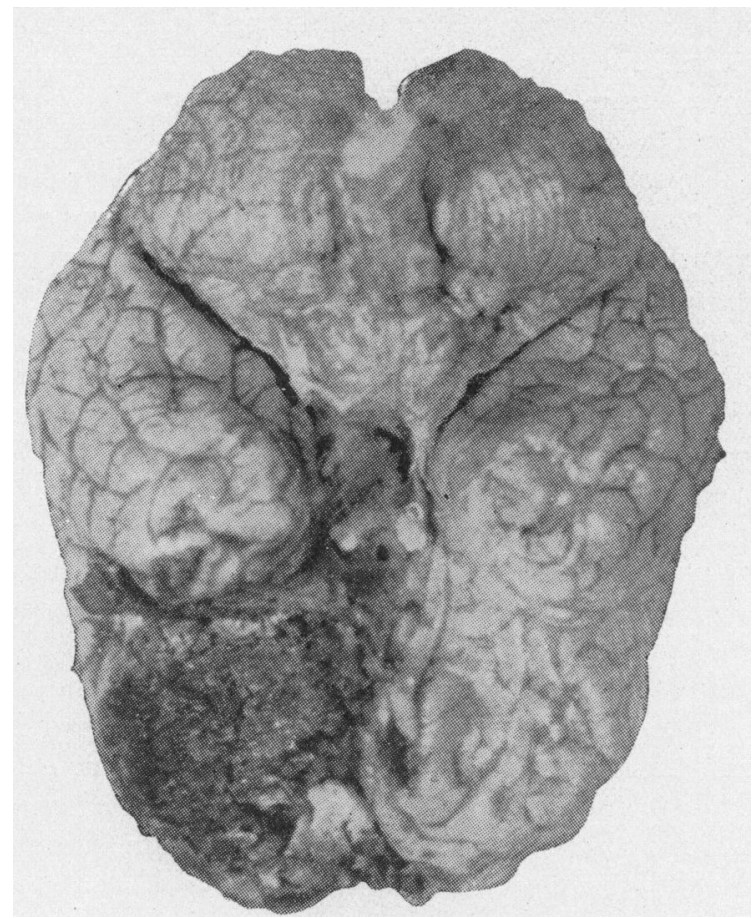

FIG. 2.

Abscess of the right frontal lobe.

"There exists, moreover, a diffuse leptomeningitis." (See Fig. 2.) The fragments of the tumour reunited weighed forty-three grams, and from the macroscopic point of view, it was nippled in the orbit, as well as in the cranial cavity, presenting at certain places spongy parts, or very hard ones.

Professor Pierre Masson, who made the anatomo-pathological examination of a piece of the neoplasm grown into the skull, gave me the following report.

"The tumour has an hemispheric form, and is amalgamated with the orbital roof. It is very hard, and must be divided into slices with a fine saw." 
"It contains two regions of different structure. One external or cortical, formed by a very compact bony tissue having narrow Haversian canals and resembling that of the diaphysis of a long bone. The other, deep, is formed by a tissue of variable structure according to the points: this tissue is fibrous in places, very dense and having large capillary vessels running through it. Elsewhere osteoid galleries spring up in places. These osteoid galleries are continuous externally with the compact bone which forms the superficial shell of the tumour. Between these young galleries, there exists only fibrous tissue and vessels, no red marrow."

"The bony tissue seems to be altogether stable in the compact region. The Haversian canals are not bordered by osteoblasts in epithelioid arrangement order,-sign of bony increase-nor by myeloplax included in the lacunae of Howship,-sign of resorption. We find pictures of increase and resorption (these very rare) only in the deep region."

"This tumour is a pure osteoma springing from the direct and progressive ossification of an initial fibroma. In no place the tumour presented, either on its surface or in its interstices the least inflammatory lesion."

In appreciating the facts exposed in this case report, I shall avoid repeating as much as possible what I have already said in the publication of my first paper; though, I shall recall that my patient never had formerly any infections of the nose, that she never received any trauma on the naso-frontal region, and that her orbital osteoma had sprung from the ethmoid bone without any apparent cause. This tumour, particularly hard, had been totally removed in 1925. Desirous to know then its imperviousness to the $\mathrm{X}$-rays, I had it radiographed with the head of a small statue in ivory, of a size relatively equal to the neoplasm, which had given the same opacity for the two objects (see my illustration).*

From the history of the patient, cure maintained itself during six years; though it would be logical to believe that a recurrence had begun before October, 1931, and that the first manifestations had passed unperceived. As we all know on the other hand that osteomas of the orbit have a rather slow evolution, the neoplasm of the patient would have attained with difficulty a volume of forty-three grams in the space of sixteen months.

The anatomo-pathological examination has furnished information of a special interest. Indeed, it has been demonstrated that the tumour, developed on the old cicatricial tissue of the ethmoid boneobservation made during operation-had at first been a fibroma which, in process of time, had progressively undergone ossification. Contrary to what I had found during the first operation, where the osteoma, very hard, had invaded the orbit in pushing the eye forward,

\footnotetext{
*Annales d'oculistique, Paris, Vol. CLXVII, p. 830. October, 1930.
} 
its recurrence offered a semi-spongy, semi-ivory-like consistency prolonging itself in depth in the cranial cavity, with only a slight exophthalmos.

Let us see now in what manner the brain has been infected. At diaphanoscopy, on Roentgenogram, and especially at autopsy, the frontal sinus corresponding to the tumour had been found absolutely normal. We must then admit that the infection had its point of origin in the nasal fossa, and that it slowly reached the meninges-by the posterior way of the neoplasm most probably. If the patient had never presented retro-bulbar abscess, it is because the infection, chronic at the first outset, with a very slow evolution, had never manifested itself under an acute or sub-acute form, consecutive to a severe rhinitis for example. Though the fragment of the intra-cranial tumour examined under the microscope has not shown any inflammatory signs, this fact does not invalidate the hypothesis that the microbes coming from the nose had proceeded to the brain by the cortical part of the osteoma. The cerebral pulsations, transmitted to the meninges in contact with the tumour had produced in time a wearing out of the dura-mater, by which infection then propagated itself to the frontal lobe. It would not be reasonable to suppose that the infection had followed the cribriform plate of the ethmoid bone to reach the brain, because the patient, since her first operation, never had ethmoiditis, at my examination the right nasal fossa was normal, and at the autopsy no pathological finding was observed in the region of the crista galli apophysis.

I regret not to be able to furnish a microscopic report of the pus evacuated from the abscess of the brain. The virulence of this pus was very strong, since twenty-eight hours after operation, the patient died with a temperature of $103 \cdot 1^{\circ} \mathrm{F}$. Moreover Associate Professor Simard, who has practised researches on cerebral sections limiting the abscess, found that this tissue was parcelled and strongly infiltrated with red corpuscles, that it was carpeted by a purulent layer, and finally that there existed a diffuse leptomeningitis.

At the time of the clinical examination, I observed that the right nasal fossa, although quite free, presented anosmia,-and that smell was normal on the left. This phenomenon is explained by the destruction of the olfactory bulb and bundles, consecutive to the abscess of the corresponding frontal lobe.

I shall underline the fact that in spite of the fairly considerable development of the cranial osteoma, the papillae, on ophthalmoscopic examination were not choked, and that on lumbar tapping, the liquid escaped without pressure. Moreover, vision of the right eye had always remained good, since the orbital neoplasm had invaded the superior part of this cavity only, without coming in contact with the optic nerve. 
The clinical symptoms, and the Roentgenogram examination have not allowed me to make a diagnosis of an abscess of the frontal lobe, for the headaches at this region, could well have been due to the tumour, and the rise of temperature, as well as vomiting, to a reaction of the meninges. Though, if I had thought of such a complication-observed for the first time-it would have been instructive to see what a ventriculography would have given.

To sum up this case report, I shall say :-

1. That my patient, in 1925, had had radical operation for an osteoma of the orbit, developed on the ethmoid bone, having the consistency of ivory ;

2. That the cure was maintained apparently until 1931 ;

3. That from this epoch a recurrence manifested itself in the form of a fibroma starting from the nose;

4. That this fibroma underwent ossification;

5. That this tumour invaded at first the superior half of the orbit, and then the cranial cavity;

6. That the nasal infection propagated itself by way of the tumour to the brain;

7. That during the operation an abscess of the frontal lobe was discovered;

8. And finally, that this patient died of diffuse leptomeningitis twenty-eight hours after intervention.

\section{BIBLIOGRAPHY}

Tchilinghiroff, R. I.-De l'ostéome de l'orbite. Thèse de Bordeaux, No. 67, 1900. de Taranto, I. M.-Les ostéomes de l'orbite. Thèse de Paris, No. 268, 1901.

Lagrange, F.-Traité des tumeurs de l'oeil, de l'orbite et des annexes. Tome II, p. 567, G. Steinheil, éditeur, Paris, 1904.

Roy, J. N.-Calcified fibroma of the orbit. The Ophthalmoscope, Vol. VII, p. 15, January, 1909.

Lagrange, F.-Encyclopédie française d'ophtalmologie, Tome VIII, p. 728 , Octave Doin et Fils, éditeurs, Paris, 1909.

Roy, J. N.-Volumineux ostéome de l'orbite. Ann. d'ocul., Tome CLXVII, p. 825, October, 1930.

Paralysie faciale périphérique consécutive à une engelure de la joue. Les Ann. d'Oto-Laryngol., Tome I, p. 745, Juillet, 1931. 